\title{
Effect of Atorvastatin on Serum Levels of Periostin in Asthma - A Placebo Controlled Randomized Clinical Trial
}

Samrad Mehrabi ( $\square$ mehrabis@sums.ac.ir)

Shiraz University of Medical Sciences https://orcid.org/0000-0002-8231-7815

Jalal Torkan

Shiraz University of Medical Sciences

Massood Hosseinzadeh

Shiraz University of Medical Sciences

Research article

Keywords: Asthma, Atorvastatin, Eosinophils, Periostin

Posted Date: February 9th, 2021

DOI: https://doi.org/10.21203/rs.3.rs-200525/v1

License: (c) (i) This work is licensed under a Creative Commons Attribution 4.0 International License.

Read Full License 


\section{Abstract}

Background: Asthma is a common pulmonary disease with a high morbidity rate. Considering the role of inflammation in the disease induction and severity, and the anti-inflammatory effect of atorvastatin, we aimed to investigate the effect of atorvastatin on serum level of periostin and eosinophil in patients with asthma, in order to introduce the usefulness of this drug on reducing the inflammation in patients with asthma.

Methods: In a blinded randomized control trial, 80 patients with definite diagnosis of asthma were enrolled into the intervention or placebo group, who received $40 \mathrm{mg} /$ day atorvastatin and similar placebo every day for 8 weeks. Spirometric measurements were performed and asthma control test was completed by the patients at baseline, after 4 weeks, and at the end of study (after 8 weeks). The primary outcomes of the study were serum eosinophil count and periostin levels.

Results: 40 patients were analyzed in each group and their data were analyzed. Mean asthma control scores in the intervention and placebo groups were similar at baseline $(17.95 \pm 3.75$ vs. $17.98 \pm 3.77$; $\mathrm{P}>0.05)$ and improved in the intervention group $(19.88 \pm 3.28 ; \mathrm{P}<0.001)$, but remained unchanged in the placebo group $(18.6 \pm 3.26 ; P=0.09)$. Neither the spirometric changes, nor the serum levels of eosinophil count and periostin were significantly different between the groups $(P>0.05)$.

Conclusions: Although the intervention group had improved asthma control score after the intervention, this effect could be because of the indirect effect of atorvastatin, as the spirometric measurements and inflammatory markers did not change significantly and were not different between the placebo and intervention groups. Further studies with longer follow-ups may show changes in spirometric parameters by atorvastatin or its effect on other inflammatory markers.

\section{Background}

Asthma is a common chronic disease, affecting both children and adults, with a worldwide prevalence of more than 300 million people, estimated to rise year after year [1]. It imposes a great social impact, resulting in several work and school absent days, in addition to great economic burden (about 3100 USD in USA or 1900 USD in Europe annually per a patient with asthma), while more than half of asthmarelated costs is caused by a small percentage of patients (less than 10\%) with severe asthma [2]. Several guidelines have suggested different diagnostic criteria for asthma, while most confirm suspecting asthma by signs and symptoms, including wheezing, cough, dyspnea, and chest tightness and confirming diagnosis by diagnostic tests, like spirometry[3].

The main symptoms result from bronchoconstriction, mucus hypersecretion, airway inflammation, and hyper-responsiveness [4]. Several inflammatory cells, such as mast cells and lymphocytes, releasing specific cytokines (like interleukins), are increased in the airways of patients with asthma and chemical mediators, like macrophage-derived chemokines, are expressed in airway's epithelial cells and help attract inflammatory cells to the patient's airways[5]. Eosinophils are differentiated form of granulocytes that 
release toxic granule proteins and reactive oxygen species (ROS) for defending pathogens, as well as chemokines, cytokines, lipid mediators, and other growth factors, and their increase in blood eosinophilia- can cause airway damage and remodeling and is associated with severe asthma [6, 7]. However, eosinophilia cannot be used as a diagnostic marker of asthma, as it can be observed in several inflammatory conditions[8]; accordingly, research has continued on more specific markers for diagnosis of asthma.

Periostin, an extracellular matrix protein of fasciclin family, is identified as a downstream molecule of cytokines (IL-4 and IL-13), attributed to subepithelial fibrosis in bronchial asthma[9]. It has been introduced as a systemic marker of eosinophilic airway inflammation [10] and is overexpressed in the lungs of patients with respiratory disorders, specifically asthma [11]. Sputum and serum periostin levels have been associated with sputum eosinophil proportions, but it may have insufficient ability in prediction of eosinophilic asthma [12]. Research on the role of periostin in progression of asthma and using its serum levels as a marker of asthma severity or treatment efficacy is still active [13].

The complex etiology of asthma has resulted in difficulty of treatment and continuing search for a more appropriate treatment, targeting inflammation [14]. Atorvastatin has shown beneficiary effects on reduction of inflammatory cell infiltration and airway hyperresponsiveness, through reducing the serum levels of inflammatory markers, such as transforming growth factor (TGF) $-\beta 1$ and matrix metalloproteinases (MMP)-9, as well as immunoglobulins, such as IgE and IgG in animal studies $[15,16]$. However, human studies have shown dissimilar results in view of its efficacy on pulmonary function [1720]. Therefore, in the present study, we aimed to investigate the effect of atorvastatin on serum level of inflammatory markers, spirometric parameters, and asthma control in patients with asthma, in order to determine the usefulness of this drug in treatment of asthma.

\section{Materials And Methods}

\section{Study design}

The present study was a triple-blind placebo-controlled randomized clinical trial (RCT), conducted in Shiraz, Iran, from January to July 2018. The study protocol was approved by the Ethics Committee of Shiraz University of Medical Sciences (Ethics code: IR.SUMS.MED.REC.1396.111), and was recorded in IRCT website by the code: IRCT2017102216367N2. The trial protocol can be accessed from https://www.irct.ir/user/trial/15332/view. The study adheres to CONSORT guidelines. The study sample size was calculated at 34 in each group considering standardized effect size of 0.65 , using the results of the study by Hothersall and colleagues[17], and considering $95 \%$ confidence interval $(95 \% \mathrm{Cl})$, study power of $80 \%$, and the chance of lost to follow-up, 40 patients were included in each group.

Patients who referred to the Lung Clinic of Shahid Faghihi Hospital and Motahari Clinic during the study period were considered for inclusion into the study, if they aged 18-60 years, had a history of asthma for more than 1 year, no history of smoking during the past 3 months or $<10$ pack/year, no history of lower 
respiratory tract infection during the past 4 weeks, or using oral steroids or statins during the past 3 months. Also, the patients using drugs interacting with statins, such as antifungal drugs, macrolide antibiotics, cyclosporine, gemfibrozil, verapamil, and amiodarone, patients with hepatitis or active hepatic disease, myopathy, or myositis, and lactating, or pregnant women were not included into the study. Diagnosis of asthma was made by the pulmonology specialist according to history taking, physical examination, pulmonary tests, and imaging. The design and objectives of the study were explained to all participants and written informed consent was obtained from those who were willing to participate in the study and they were clarified that they were free to leave the study whenever they wished to.

A statistician, who was not involved in other steps of the study, generated "A" and "B" codes for 80 patients using random allocation software. The researcher collecting the data, the statistician who analyzed the data, and the nurse who gave the drugs to the patients were not aware of the group allocations and the included patients were enrolled into the intervention and placebo groups based on the codes. The intervention group received $40 \mathrm{mg}$ atorvastatin (Sobhan Iran Pharma Co., Iran) every day for 8 weeks and the placebo group received placebo with the same pattern. The placebo was prepared by the Schools of Pharmacy of Shiraz University of Medical Sciences and was completely similar in shape and color to atorvastatin, but only contained neutral ingredients without pharmacological effect. The patients were excluded from the study if they did not adhere the prescribed drugs routinely or did not refer for any of the follow-up examinations, or developed any complications related to the administered drug, or refused to continue the study. The patient recruitment stages are shown in Fig. 1.

All the patients underwent spirometric examination at baseline, after 4, and 8 weeks, and forced expiratory volume in first second $\left(\mathrm{FEV}_{1}\right)$, forced vital capacity ( $\left.F V C\right), \mathrm{FEV}_{1} / \mathrm{FVC}$, total lung capacity (TLC), residual volume (RV), RV/TLC, total airway resistance (Raw), and specific airway resistance (sRaw) were recorded for each patient. Before and after the intervention (at baseline and after 8 weeks), the patients completed the asthma control test (ACT) [21]. This test is a simple method for assessing adequacy of asthma control by five items, which provides a numerical score for assessment of asthma control during the previous 4 weeks. The validity of the Persian version of this test, used in this study, has been confirmed previously [22]. Furthermore, at baseline and the end of the study (after 8 weeks), one venous blood sample was taken from the patients, centrifuged at $300 \mathrm{G}$ after 10 minutes, and its serum was separated. Then, the samples were kept at -70 degrees and serum parameters, including white blood cells (WBC), serum eosinophil percentage, polymorphonuclear percentage, hemoglobin, total cholesterol, low density lipoprotein $(\mathrm{LDL})$, high density lipoprotein $(\mathrm{HDL})$, triglyceride, creatinine, alanine transaminase (ALT), aspartate transaminase (AST), alkaline phosphatase (ALP), and serum periostin were measured using Thermoscientist USA LOT 0070122017 REF: EHPOSTIN and AWARENESS ELISA reader device. After drawing the standard figures and defining cut-offs, the values were reported in $\mathrm{ng} / \mathrm{mL}$.

The primary outcomes of the study were considered as serum eosinophil count and periostin levels and the secondary outcomes of the study were considered as spirometric changes and the scores of ACT. Also, the patients' demographics, including age, sex, weight, height, and smoking status were extracted from the medical records. Participants' ages were categorized into below and above 50, and smoking 
status was recorded as positive or negative, while former and current smoking were considered as positive. Body mass index (BMI) was calculated based on the recorded weight and height.

\section{Statistical analysis}

The collected data were first input into the statistical software IBM SPSS Statistics for Windows version 23.0 (IBM Corp. 2014. Armonk, NY: IBM Corp.), used for analysis. The descriptive results were presented by frequency (percentage) and mean \pm standard deviation (SD). One-sample Kolmogorov-Smirnov test was used to assess the normal distribution of the data. Continuous variables were compared between the groups using $t$ test and between the intervals using paired $t$ test or repeated measures ANOVA. Categorical variables were compared using Chi-square test. $P$ values of 0.05 or less were considered as statistically significant.

\section{Results}

The data of 40 patients were assigned and analyzed in each group. The demographic characteristics of the groups, including age categories, sex distribution, BMI, and smoking status were not statistically different between the intervention and placebo groups $(P>0.05$, Table 1$)$. 
Table 1

Distribution of demographic and general variables in both intervention and control groups

\begin{tabular}{|c|c|c|c|c|}
\hline \multirow[t]{2}{*}{ Variable Categories } & & \multicolumn{2}{|l|}{ Group } & \multirow[t]{2}{*}{$P$ value } \\
\hline & & intervention & Placebo & \\
\hline \multirow[t]{3}{*}{ Age category, years } & Mean \pm SD & $44.8 \pm 10.4$ & $43.3 \pm 11.6$ & $0.54^{*}$ \\
\hline & $<50$ years old & $28(70 \%)$ & $29(72.5 \%)$ & \multirow[t]{2}{*}{$0.81^{\dagger}$} \\
\hline & $\geq 50$ years old & $12(30 \%)$ & $11(27.5 \%)$ & \\
\hline \multirow[t]{2}{*}{ Sex distribution } & Male & 20 (51.3\%) & $14(36.8 \%)$ & \multirow[t]{2}{*}{$0.2^{\dagger}$} \\
\hline & Female & $19(48.7 \%)$ & $24(63.2 \%)$ & \\
\hline \multirow[t]{5}{*}{ Body mass index } & Mean \pm SD & $27.15 \pm 5.04$ & $28.07 \pm 5.4$ & $0.44^{*}$ \\
\hline & Underweight & $1(2.5 \%)$ & $2(5 \%)$ & \multirow[t]{4}{*}{$0.28^{\dagger}$} \\
\hline & Normal & $13(32.5 \%)$ & $5(15 \%)$ & \\
\hline & Overweight & $15(37.5 \%)$ & $15(40 \%)$ & \\
\hline & Obese & $11(27.5 \%)$ & $16(40 \%)$ & \\
\hline \multirow[t]{2}{*}{ Smoking status } & No & $21(52.5 \%)$ & $15(40 \%)$ & \multirow[t]{2}{*}{$0.26^{\dagger}$} \\
\hline & Yes & 19 (47.5\%) & $24(60 \%)$ & \\
\hline
\end{tabular}

According to the results of independent samples $t$ test, mean \pm SD of ACT score was not statistically different between the groups at baseline: $17.95 \pm 3.75$ in the intervention group and $17.98 \pm 3.77$ in placebo group $(\mathrm{P}=0.98)$. At the end of the study, the results of paired $t$ test showed that mean $\pm S D$ of ACT score improved significantly in the intervention group $(19.88 \pm 3.28 ; \mathrm{P}<0.001)$, but remained unchanged in the placebo group $(18.6 \pm 3.26 ; P=0.09)$. Although the mean scores after intervention were not different between the groups ( $P=0.09$; based on the results of independent samples $t$ test), the change in the scores was significantly higher in the intervention group compared with the placebo group $(13.25 \pm 2.96$ vs. $5.19 \pm 2.41$, respectively; $P=0.038)$. Comparison of asthma control scores between the groups is shown in Fig. 2.

Comparison of the spirometric parameters between the groups showed that only TLC and RV showed statistically significant reduction in the intervention group (both $P=0.02$ ), while they remained unchanged in the placebo group $(P>0.05)$; meanwhile, neither mean TLC and RV nor other parameters were different between the groups $(P>0.05$, Table 2$)$. 
Table 2

Mean spirometric parameters at baseline, 1 month and 2 months after intervention in two groups

\begin{tabular}{|c|c|c|c|c|}
\hline \multirow[t]{2}{*}{ Spirometric parameter } & \multirow[t]{2}{*}{ Time } & \multicolumn{2}{|l|}{ Group } & \multirow[t]{2}{*}{$P$ value } \\
\hline & & intervention & Placebo & \\
\hline \multirow[t]{4}{*}{$\mathrm{FEV}_{1}$} & Baseline & $80.5 \pm 19.4$ & $77.6 \pm 21.1$ & 0.51 \\
\hline & 1 month after intervention & $82.8 \pm 17.8$ & $78.2 \pm 18.4$ & 0.26 \\
\hline & 2 months after intervention & $92.7 \pm 50.7$ & $75 \pm 22.9$ & 0.05 \\
\hline & P value $^{\dagger}$ & 0.14 & 0.58 & $0.08^{\ddagger}$ \\
\hline \multirow[t]{4}{*}{ FVC } & Baseline & $85.7 \pm 14.5$ & $82.6 \pm 17.2$ & 0.39 \\
\hline & 1 month after intervention & $86.9 \pm 14.7$ & $82.9 \pm 15.6$ & 0.24 \\
\hline & 2 months after intervention & $87.3 \pm 15.2$ & $81.8 \pm 16.3$ & 0.13 \\
\hline & P value $^{\dagger}$ & 0.15 & 0.89 & $0.23^{\ddagger}$ \\
\hline \multirow[t]{4}{*}{$\mathrm{FEV}_{1} / \mathrm{FVC}$} & Baseline & $77.8 \pm 13.9$ & $77.6 \pm 10.9$ & 0.94 \\
\hline & 1 month after intervention & $79.3 \pm 10.5$ & $78.6 \pm 9.7$ & 0.77 \\
\hline & 2 months after intervention & $81.1 \pm 9.2$ & $78.1 \pm 10.5$ & 0.19 \\
\hline & P value $^{\dagger}$ & 0.11 & 0.73 & $0.48^{\ddagger}$ \\
\hline \multirow[t]{4}{*}{ TLC } & Baseline & $97.9 \pm 23.1$ & $95.1 \pm 16.3$ & 0.53 \\
\hline & 1 month after intervention & $97.9 \pm 20.9$ & $95.5 \pm 19.2$ & 0.6 \\
\hline & 2 months after intervention & $96.4 \pm 18.3$ & $94.1 \pm 15.5$ & 0.57 \\
\hline & P value $^{\dagger}$ & 0.022 & 0.6 & $0.5^{\ddagger}$ \\
\hline \multirow[t]{4}{*}{ RV } & Baseline & $126.3 \pm 59.6$ & $119 \pm 45.4$ & 0.54 \\
\hline & 1 month after intervention & $122.1 \pm 50$ & $113.3 \pm 43.3$ & 0.4 \\
\hline & 2 months after intervention & $114.4 \pm 41.7$ & $108.6 \pm 37.5$ & 0.53 \\
\hline & P value $^{\dagger}$ & 0.019 & 0.23 & $0.46^{\ddagger}$ \\
\hline
\end{tabular}

\footnotetext{
${ }^{*}$ Between-group difference tested by independent samples $t$ test at each interval; ${ }^{+}$Within-group differences among the three intervals based on the results of repeated measures ANOVA; ${ }^{\ddagger}$ Betweengroup difference of the change in each parameter by time based on the results of repeated measures ANOVA
}

Abbreviations: $\mathrm{FEV}_{1}$; forced expiratory volume, FVC; forced vital capacity, TLC; total lung capacity, RV; residual volume, Raw; total airway resistance, sRaw; specific airway resistance 


\begin{tabular}{|c|c|c|c|c|}
\hline \multirow[t]{4}{*}{$\mathrm{RV} / \mathrm{TLC}$} & Baseline & $120.3 \pm 36.4$ & $121.9 \pm 31.7$ & 0.83 \\
\hline & 1 month after intervention & $119.1 \pm 37.9$ & $121.3 \pm 29.1$ & 0.77 \\
\hline & 2 months after intervention & $115.3 \pm 32.2$ & $121.9 \pm 29.2$ & 0.35 \\
\hline & P value $^{\dagger}$ & 0.09 & 0.91 & $0.67^{\ddagger}$ \\
\hline \multirow[t]{4}{*}{ Raw } & Baseline & $209.7 \pm 130.8$ & $179.7 \pm 108.9$ & 0.27 \\
\hline & 1 month after intervention & $206.5 \pm 139.3$ & $191.3 \pm 117.7$ & 0.59 \\
\hline & 2 months after intervention & $197.9 \pm 148.6$ & $193.1 \pm 117.9$ & 0.88 \\
\hline & P value $^{\dagger}$ & 0.69 & 0.38 & $0.69^{\ddagger}$ \\
\hline \multirow[t]{4}{*}{ sRaw } & Baseline & $327.4 \pm 155.2$ & $223.7 \pm 168.1$ & 0.66 \\
\hline & 1 month after intervention & $223.7 \pm 138.8$ & $213.7 \pm 139.5$ & 0.75 \\
\hline & 2 months after intervention & $218.2 \pm 144.6$ & $218.3 \pm 156.9$ & 0.99 \\
\hline & P value $^{\dagger}$ & 0.11 & 0.28 & $0.83^{\ddagger}$ \\
\hline \multicolumn{5}{|c|}{$\begin{array}{l}\text { *Between-group difference tested by independent samples } t \text { test at each interval; }{ }^{+} \text {Within-group } \\
\text { differences among the three intervals based on the results of repeated measures ANOVA; }{ }^{*} \text { Between- } \\
\text { group difference of the change in each parameter by time based on the results of repeated measures } \\
\text { ANOVA }\end{array}$} \\
\hline \multicolumn{5}{|c|}{$\begin{array}{l}\text { Abbreviations: } \mathrm{FEV}_{1} \text {; forced expiratory volume, } \mathrm{FVC} \text {; forced vital capacity, TLC; total lung capacity, RV; } \\
\text { residual volume, Raw; total airway resistance, sRaw; specific airway resistance }\end{array}$} \\
\hline
\end{tabular}

Considering serum parameters, mean WBC count, total cholesterol, HDL, LDL, and TG showed statistically significant change after intervention compared with baseline values in the intervention group $(P=0.016$, $0.005,0.023,0.015,0.043$, respectively), but not in the placebo group $(P>0.05)$; however, the difference between the groups was not statistically significant in none of serum parameters $(P>0.05$, Table 3$)$. 
Table 3

Mean and standard deviation of laboratory findings at baseline, 1 month and 2 months after intervention in two groups

\begin{tabular}{|c|c|c|c|c|}
\hline \multirow[t]{2}{*}{ Indicator } & \multirow[t]{2}{*}{ Time } & \multicolumn{2}{|l|}{ Group } & \multirow{2}{*}{$\begin{array}{l}P \\
\text { value }\end{array}$} \\
\hline & & intervention & Placebo & \\
\hline \multirow[t]{3}{*}{ White blood cell count $\times 1000$, mean \pm SD } & Baseline & $6.99 \pm 1.56$ & $8.88 \pm 12.32$ & 0.34 \\
\hline & $\begin{array}{l}\text { After } \\
\text { intervention }\end{array}$ & $6.46 \pm 1.65$ & $6.81 \pm 1.77$ & 0.37 \\
\hline & P value $^{\dagger}$ & 0.016 & 0.29 & $0.26^{\ddagger}$ \\
\hline \multirow[t]{3}{*}{ Eosinophil percentage, mean \pm SD } & Baseline & $17.98 \pm 9.9$ & $8.11 \pm 4.63$ & 0.32 \\
\hline & $\begin{array}{l}\text { After } \\
\text { intervention }\end{array}$ & $8.3 \pm 4.21$ & $8.06 \pm 5.37$ & 0.8 \\
\hline & P value $^{\dagger}$ & 0.33 & 0.82 & $0.34^{\ddagger}$ \\
\hline \multirow[t]{3}{*}{ Total cholesterol $(\mathrm{mg} / \mathrm{dL})$, mean \pm SD } & Baseline & $162 \pm 52.2$ & $150.8 \pm 42.4$ & 0.29 \\
\hline & $\begin{array}{l}\text { After } \\
\text { intervention }\end{array}$ & $\begin{array}{l}134.15 \pm \\
29.9\end{array}$ & $156.9 \pm 44$ & 0.009 \\
\hline & P value $^{\dagger}$ & 0.005 & 0.35 & $0.026^{\ddagger}$ \\
\hline \multirow[t]{3}{*}{$\begin{array}{l}\text { High density lipoprotein }(\mathrm{mg} / \mathrm{dL}) \text {, mean } \\
\pm \mathrm{SD}\end{array}$} & Baseline & $\begin{array}{l}40.58 \pm \\
11.09\end{array}$ & $44.65 \pm 9.32$ & 0.31 \\
\hline & $\begin{array}{l}\text { After } \\
\text { intervention }\end{array}$ & $44 \pm 7.88$ & $41.4 \pm 8.2$ & 0.17 \\
\hline & P value $^{\dagger}$ & 0.023 & 0.16 & $0.048^{\ddagger}$ \\
\hline \multirow[t]{3}{*}{$\begin{array}{l}\text { Low density lipoprotein }(\mathrm{mg} / \mathrm{dL}) \text {, mean } \pm \\
\text { SD }\end{array}$} & Baseline & $110.15 \pm 41$ & $\begin{array}{l}101.98 \pm \\
29.3\end{array}$ & 0.31 \\
\hline & $\begin{array}{l}\text { After } \\
\text { intervention }\end{array}$ & $\begin{array}{l}94.35 \pm \\
35.7\end{array}$ & $\begin{array}{l}101.05 \pm \\
29.66\end{array}$ & 0.37 \\
\hline & P value $^{\dagger}$ & 0.015 & 0.79 & $0.029^{\ddagger}$ \\
\hline \multirow[t]{3}{*}{$\begin{array}{l}\text { Aspartate aminotransferase (IU/L), } \\
\text { mean } \pm \text { SD }\end{array}$} & Baseline & $\begin{array}{l}16.53 \pm \\
6.51\end{array}$ & $\begin{array}{l}18.78 \pm \\
15.82\end{array}$ & 0.41 \\
\hline & $\begin{array}{l}\text { After } \\
\text { intervention }\end{array}$ & $\begin{array}{l}18.08 \pm \\
11.28\end{array}$ & $17.32 \pm 9.66$ & 0.75 \\
\hline & P value $^{\dagger}$ & 0.4 & 0.47 & $0.67^{\ddagger}$ \\
\hline
\end{tabular}




\begin{tabular}{|c|c|c|c|c|}
\hline \multirow[t]{3}{*}{$\begin{array}{l}\text { Alanine aminotransferase (IU/L), mean } \pm \\
\text { SD }\end{array}$} & Baseline & $\begin{array}{l}16.8 \pm \\
13.52\end{array}$ & $13.5 \pm 8.04$ & 0.18 \\
\hline & $\begin{array}{l}\text { After } \\
\text { intervention }\end{array}$ & $15.3 \pm 8.8$ & $15 \pm 10.6$ & 0.89 \\
\hline & P value $^{\dagger}$ & 0.51 & 0.22 & $0.37^{\ddagger}$ \\
\hline \multirow[t]{3}{*}{ Periostin $(\mathrm{ng} / \mathrm{mL})$, mean $\pm \mathrm{SD}$} & Baseline & $9.41 \pm 7.79$ & $14.25 \pm 2.96$ & 0.14 \\
\hline & $\begin{array}{l}\text { After } \\
\text { intervention }\end{array}$ & $\begin{array}{l}15.34 \pm \\
11.43\end{array}$ & $\begin{array}{l}16.06 \pm \\
12.67\end{array}$ & 0.79 \\
\hline & P value $^{\dagger}$ & 0.06 & 0.26 & $0.25^{\ddagger}$ \\
\hline
\end{tabular}

\section{Discussion}

In the present RCT, we compared the results of 8-week administration of $40 \mathrm{mg} /$ day atorvastatin on asthma control and spirometric and serum parameters of patients with asthma. The results showed that asthmatic control score significantly improved in the intervention group, but did not change in placebo group, while neither spirometric parameters, nor the serum level of periostin and eosinophil counts were different between the groups. Serum lipid profile of the patients was also evaluated before and after the intervention in order to determine patients' adherence to treatment, confirmed by the significant reduction in serum levels of total cholesterol, $\mathrm{HDL}, \mathrm{LDL}$, and triglyceride in the intervention group.

Atorvastatin is a cholesterol-lowering drug with anti-inflammatory effects and animal models have shown its efficacy on reduction of inflammatory cell infiltration and airway hyper-responsiveness $[15,16]$. However, human studies have shown controversial results considering its efficacy in treatment of asthma. Some have reported better asthma control in patients with severe asthma using statins [23, 24], while other studies, like ours, have reported no significant difference [25-27]. In the study by Fahimi and colleagues, 17 adult patients with moderate to severe asthma received $10 \mathrm{mg} /$ day atorvastatin or placebo for 4 weeks in a cross-over design study [25]. Similar to the results of the present study, they also reported no difference between spirometric parameters of the intervention or placebo group; however, there were some differences between the studies in the improvement of spirometric parameters by time in the intervention group, as they reported significant increase in the FVC $(P=0.01)$, while we detected significant reduction in TLC and RV in the intervention group, but not in FVC. These differences between the studies could be because of the different dose and duration of administered atorvastatin from our study. Alavi and others investigated the effects of $40 \mathrm{mg} /$ day atorvastatin on patients with moderate to severe asthma compared with placebo, and reported changes in spirometric parameters in each of the groups without significant difference between the groups [26], which is consistent with the results of the present study. Similar to the methods of the present study, in a previous study on 62 patients, the 
researchers randomized patients with asthma to receive $40 \mathrm{mg}$ /day atorvastatin or placebo for 8 weeks. The results showed elevated $F E V_{1}$ and $F V C$ in the placebo group after 8 weeks and elevated $F E V_{1}$ in the intervention group after 8 weeks, without significant difference between the groups in spirometric parameters [27]. The dose/duration of administration of atorvastatin in this study was similar to ours and no significant difference in spirometric parameters between the groups was also consistent with the results of our study; however, they only evaluated FEV ${ }_{1}$ and FVC, while we reported complete spirometric results and showed significant changes in TLC and RV in the intervention group. Meanwhile, as TLC and $\mathrm{RV}$ were both lower in the intervention group of our study, it could not show any improvements in this group, which is consistent with the results of previous studies $[25,27]$.

In the present study, the results of ACT showed significant improvement in asthma control scores of the intervention group (from $17.95 \pm 3.75$ to $19.88 \pm 3.28 ; P<0.001$ ), in addition to greater change in the scores in the intervention group compared with the placebo group (13.25 \pm 2.96 vs. $5.19 \pm 2.41$, respectively; $P=0.038$ ). These results confirm the beneficiary effect of the administered atorvastatin on clinical outcomes of the patients with asthma. In the study by Moini and colleagues, 62 patients with mild to moderate asthma were randomized to receive $40 \mathrm{mg} /$ day atorvastatin or placebo for 8 weeks. The results showed significant reduction in asthma control scores both in intervention and placebo groups, while there was no difference between the groups in this regard [27]. They reported mean asthma control score of the placebo group increased from $15.27 \pm 4.34$ to $17.83 \pm 4.47(P<0.001)$ and that of the intervention group from $16.78 \pm 4.11$ to $19.85 \pm 3.20(P<0.001)$ [27]. Comparing the mean values of their study with our study shows that the baseline scores of their patients were lower than ours, while the mean asthma control score after 8 weeks in the intervention group of their study $(19.85 \pm 3.20)$ was close to that reported in our study $(19.88 \pm 3.28)$. Accordingly, these results confirm the significant effect of 8 weeks administration of $40 \mathrm{mg} /$ day atorvastatin on asthma control, although this effect might not be the direct effect of the drug.

Atorvastatin has shown beneficiary effects on reducing the inflammatory markers such as tumor necrosis factor-a (TNF-a), C-reactive protein (CRP), and interleukins in other diseases, such as ischemic stroke [28], rheumatoid arthritis [29], and diabetes [30]. Accordingly, in the present study, we examined its efficacy on eosinophil count and periostin levels of patients' sera, as these are considered as important inflammatory markers in asthma [12]. Nevertheless, the results of our study showed no significant changes in eosinophil count and periostin in the groups and no difference between the intervention and placebo group in this regard. The serum eosinophil count of the placebo group in the present study was $8.11 \pm$ 4.63 at baseline and $8.06 \pm 5.37$ after 8 weeks, while in the intervention group, it was17.98 \pm 9.9 at baseline and $8.3 \pm 4.21$ after the intervention; meanwhile, there was no significant change in either groups, or significant difference between the groups at baseline or after intervention. In the study by Moini and colleagues, eosinophil count significantly reduced in the placebo group (from $221.31 \pm 134.01$ to $204.62 \pm 134.64$ ) and in the intervention group (from $244.35 \pm 154.4$ to $179.14 \pm 117.43$; both $\mathrm{P}<$ $0.001)$, which is contrary to the results of the present study. But they also reported no significant difference between the groups, which is in line with the results of the present study. In the study by 
Hothersall and colleagues, patients' outcomes were compared between the groups receiving $40 \mathrm{mg} /$ day atorvastatin for 8 weeks and placebo in a cross-over design study with 6-week washout period and the results showed significant reduction in absolute sputum macrophage count in atorvastatin group, while morning peak expiratory flow was not different between the groups [17]. The results of studies could also depend on the main treatment of the studied patients, because of the possibility of drug interactions, as in the study by Hothersall and colleagues, inhaled corticosteroids were used as the background treatment.

As described above, the few studies addressing the efficacy of atorvastatin on asthma control and inflammatory markers in the patients with asthma have reported different results. The same discrepancy in the results of studies is observed regarding the effect of other statins, like simvastatin, on asthma control and reducing inflammation in such patients [31,32]. However, a wide variety is observed among studies in terms of disease severity, parameters, and main treatments used to control asthma. These suggest that further studies are required to determine the exact efficacy of statins on asthma control. Current review studies indicated that atorvastatin reduced airway inflammation in patients with asthma, but could not improve lung function; however, the inflammatory markers studied vary among studies [20]. As studies that measured general inflammatory markers, like eosinophil count [27] and estimated sedimentation rate (ESR) [26], have declared the necessity to use more specific markers. In this study, we measured the change in serum levels of periostin on patients with asthma receiving atorvastatin for the first time, introduced as a novel biomarker in such patients [33]; but, the results of our study showed no significant difference between the groups in serum levels of periostin.

One of the limitations of the present study was that we did not examine the changes in airway tissue, endothelial, or cellular levels for a more accurate assessment of any change in patients' airway hyperresponsiveness and inflammation, and only investigated clinical and serological parameters, while histopathological assessment of the patients could guide us better in this regard. Furthermore, follow-up period of the present study was short and the sample size was limited, although they were acceptable compared with similar studies.

As the intervention was on both sexes, young and middle age patients with varying degrees of body weights, this suggested that the results of the present study could be attributed to a wide range of asthmatic patients.

\section{Conclusion}

The results of the present RCT showed no significant difference in spirometric parameters of patients with asthma receiving $40 \mathrm{mg} /$ day atorvastatin or placebo for 8 weeks. The serological results also determined neither significant change in eosinophil count or periostin levels, nor any difference between the groups in terms of these inflammatory biomarkers. The only significant difference between the groups in this study was the greater change in asthma control scores in the intervention group compared with the placebo group, as well as significant improvement in the asthma control scores in the 
intervention group. However, as far as this clinical finding was not supported by lung function test or inflammatory markers, we cannot conclude significant efficacy of atorvastatin on asthma control, and this effect was presumably because of other effects, such as increased patients' awareness on controlling asthma. Accordingly, further studies with larger sample size and longer follow-up periods are required to determine the exact effect of statins, such as atorvastatin, on asthma control. We suggest measurement of more accurate parameters, like histopathological changes in future studies.

\section{Abbreviations}

ACT: asthma control test; BMI: body mass index; TC: total lung capacity; RV: residual volume; FEV1: forced expiratory volume in first second' FVC: forced vital capacity.

\section{Declarations}

\section{Ethics approval and consent to participate}

This study was approved by the ethical committee of Vice Chancellor for Research of Shiraz University of Medical Sciences (IR.SUMS.MED.REC.1396.111) and informed consent was obtained from the participants.

\section{Consent for publication}

Not applicable.

\section{Competing interests}

The authors of the present study declare that they have no competing interests.

\section{Funding}

The present study was financially supported by Vice chancellor for research of Shiraz University of Medical Sciences (grant No. 15216). They covered the cost off periostin kit.

\section{Authors' contributions}

SM designed the study. SM, JT and MH were responsible for data collection. SM, JT and wrote the initial draft of the manuscript. SM and JT conducted the analyses. SM, JT and MH contributed to writing the manuscript. All authors contributed to the draft and approved the final version of the manuscript.

\section{Acknowledgements}

The present article was extracted from the thesis written by Jalal Torkan.

\section{Availability of data and materials}


The datasets used and/or analysed during the current study are available from the corresponding author on reasonable request.

\section{References}

1. Moraes TJ, Sears MR, Subbarao P: Epidemiology of asthma and influence of ethnicity. In: Seminars in respiratory and critical care medicine: 2018: Thieme Medical Publishers; 2018: 003-011.

2. Nunes $C$, Pereira AM, Morais-Almeida M. Asthma costs and social impact. Asthma research practice. 2017;3(1):1.

3. White J, Paton JY, Niven R, Pinnock H. Guidelines for the diagnosis and management of asthma: a look at the key differences between BTS/SIGN and NICE. Thorax. 2018;73(3):293-7.

4. Hall S, Agrawal DK. Key mediators in the immunopathogenesis of allergic asthma. Int Immunopharmacol. 2014;23(1):316-29.

5. Kumari K, Rana A. A review on epidemology, pathopysiology and management of asthma. J Appl Pharm Sci. 2012;2:55-64.

6. Carr TF, Berdnikovs S, Simon H-U, Bochner BS, Rosenwasser LJ. Eosinophilic bioactivities in severe asthma. World Allergy Organization Journal. 2016;9(1):21.

7. McBrien CN, Menzies-Gow A. The biology of eosinophils and their role in asthma. Frontiers in medicine. 2017;4:93.

8. Ramirez GA, Yacoub M-R, Ripa M, Mannina D, Cariddi A, Saporiti N, Ciceri F, Castagna A, Colombo G, Dagna L: Eosinophils from physiology to disease: a comprehensive review. BioMed research international 2018, 2018.

9. Izuhara K, Arima K, Ohta S, Suzuki S, Inamitsu M. Yamamoto K-i: Periostin in allergic inflammation. Allergology International. 2014;63(2):143-51.

10. Jia G, Erickson RW, Choy DF, Mosesova S, Wu LC, Solberg OD, Shikotra A, Carter R, Audusseau S, Hamid Q. Periostin is a systemic biomarker of eosinophilic airway inflammation in asthmatic patients. Journal of Allergy Clinical Immunology. 2012;130(3):647-54. e610.

11. Izuhara K, Conway SJ, Moore BB, Matsumoto H, Holweg CT, Matthews JG, Arron JR. Roles of Periostin in Respiratory Disorders. Am J Respir Crit Care Med. 2016;193(9):949-56.

12. Simpson JL, Yang IA, Upham JW, Reynolds PN, Hodge S, James AL, Jenkins C, Peters MJ, Jia G, Holweg CT. Periostin levels and eosinophilic inflammation in poorly-controlled asthma. BMC pulmonary medicine. 2016;16(1):67.

13. Izuhara $\mathrm{K}$, Ohta $\mathrm{S}$, Ono J. Using periostin as a biomarker in the treatment of asthma. Allergy Asthma Immunol Res. 2016;8(6):491-8.

14. Dunican EM, Fahy JV. The role of type 2 inflammation in the pathogenesis of asthma exacerbations. Annals of the American Thoracic Society. 2015;12(Supplement 2):144-9.

15. Liu MW, Liu R, Wu HY, Chen M, Dong MN, Huang YQ, Zhang CH, Wang YZ, Xia J, Shi Y. Atorvastatin has a protective effect in a mouse model of bronchial asthma through regulating tissue 
transglutaminase and triggering receptor expressed on myeloid cells-1 expression. Experimental therapeutic medicine. 2017;14(2):917-30.

16. Huang C-F, Peng H-J, Wu C-C, Lo W-T, Shih Y-L, Wu T-C. Effect of oral administration with pravastatin and atorvastatin on airway hyperresponsiveness and allergic reactions in asthmatic mice. Ann Allergy Asthma Immunol. 2013;110(1):11-7.

17. Hothersall EJ, Chaudhuri R, McSharry C, Donnelly I, Lafferty J, McMahon AD, Weir CJ, Meiklejohn J, Sattar N, Mclnnes I. Effects of atorvastatin added to inhaled corticosteroids on lung function and sputum cell counts in atopic asthma. Thorax. 2008;63(12):1070-5.

18. Braganza G, Chaudhuri R, McSharry C, Weir CJ, Donnelly I, Jolly L, Lafferty J, Lloyd SM, Spears M, Mair F. Effects of short-term treatment with atorvastatin in smokers with asthma-a randomized controlled trial. BMC pulmonary medicine. 2011;11(1):16.

19. Tse SM, Charland SL, Stanek E, Herrera V, Goldfarb S, Litonjua AA, Weiss ST, Wu AC. Statin use in asthmatics on inhaled corticosteroids is associated with decreased risk of emergency department visits. Curr Med Res Opin. 2014;30(4):685-93.

20. Yuan C, Zhou L, Cheng J, Zhang J, Teng Y, Huang M, Adcock IM, Barnes PJ, Yao X. Statins as potential therapeutic drug for asthma? Respiratory research. 2012;13(1):108.

21. Nathan RA, Sorkness CA, Kosinski M, Schatz M, Li JT, Marcus P, Murray JJ, Pendergraft TB. Development of the asthma control test: a survey for assessing asthma control. Journal of Allergy Clinical Immunology. 2004;113(1):59-65.

22. Sigari N, Sigari N, Ghasri H, Rahimi E, Mohammadi S. Validation of Persian version of asthma control test based on new global initiative for asthma guidelines. Tanaffos. 2011;10(4):49.

23. Zeki AA, Oldham J, Wilson M, Fortenko O, Goyal V, Last M, Last A, Patel A, Last JA, Kenyon NJ. Statin use and asthma control in patients with severe asthma. BMJ open. 2013;3(8):e003314.

24. Huang CC, Chan WL, Chen YC, Chen TJ, Chou KT, Lin SJ, Chen JW, Leu HB. Statin use in patients with asthma-a nationwide population-based study. Eur J Clin Invest. 2011;41(5):507-12.

25. Fahimi F, Salamzadeh J, Jamaati H, Sohrabi S, Fakharian A, Mohammadtaheri Z. Do statins improve lung function in asthmatic patients? A randomized and double-blind trial. Iranian Journal of Pharmaceutical Sciences. 2009;5(1):13-20.

26. Alavi S-A, Nejatifar F, Forghanparast K, SOBHANI A, MORTAZ G. Effect of Atorvastatin on Indices of Chronic Asthma in Patients under Treatment with High Dose Inhaled Steroid or Oral Steroid. 2010.

27. Moini A, Azimi G, Farivar A. Evaluation of atorvastatin for the treatment of patients with asthma: a double-blind randomized clinical trial. Allergy Asthma Immunol Res. 2012;4(5):290-4.

28. Tuttolomondo A, Di Raimondo D, Pecoraro R, Maida C, Arnao V, Della Corte V, Simonetta I, Corpora F, Di Bona D, Maugeri R. Early high-dosage atorvastatin treatment improved serum immuneinflammatory markers and functional outcome in acute ischemic strokes classified as large artery atherosclerotic stroke: a randomized trial. Medicine 2016, 95(13).

29. McCarey DW, McInnes IB, Madhok R, Hampson R, Scherbakova O, Ford I, Capell HA, Sattar N. Trial of Atorvastatin in Rheumatoid Arthritis (TARA): double-blind, randomised placebo-controlled trial. The 
Lancet. 2004;363(9426):2015-21.

30. Talaei A, Mahmoudpoor M, Shahdost M. The Effect of Atorvastatin on Inflammatory Markers in Patients with Type Two Diabetes. Journal of Arak University of Medical Sciences. 2018;21(4):40-7.

31. Gu W, Cui R, Ding T, Li X, Peng J, Xu W, Han F, Guo X. Simvastatin alleviates airway inflammation and remodelling through up-regulation of autophagy in mouse models of asthma. Respirology. 2017;22(3):533-41.

32. Tulbah AS, Ong HX, Colombo P, Young PM, Traini D. Could simvastatin be considered as a potential therapy for chronic lung diseases? A debate on the pros and cons. Expert Opin Drug Deliv. 2016;13(10):1407-20.

33. Matsumoto H. Serum periostin: a novel biomarker for asthma management. Allergology International. 2014;63(2):153-60.

\section{Figures}

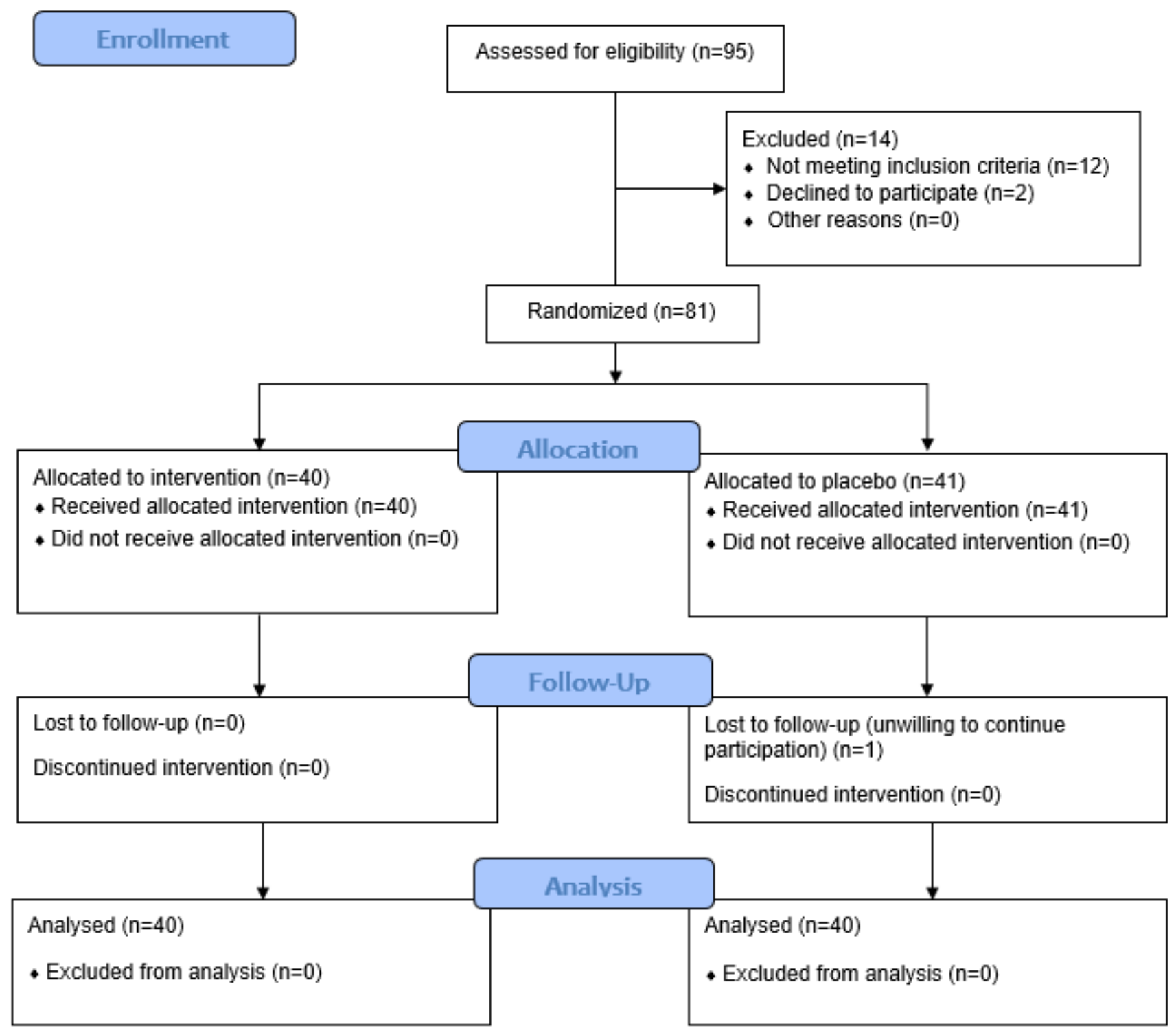


Figure 1

Flow diagram for study enrollment

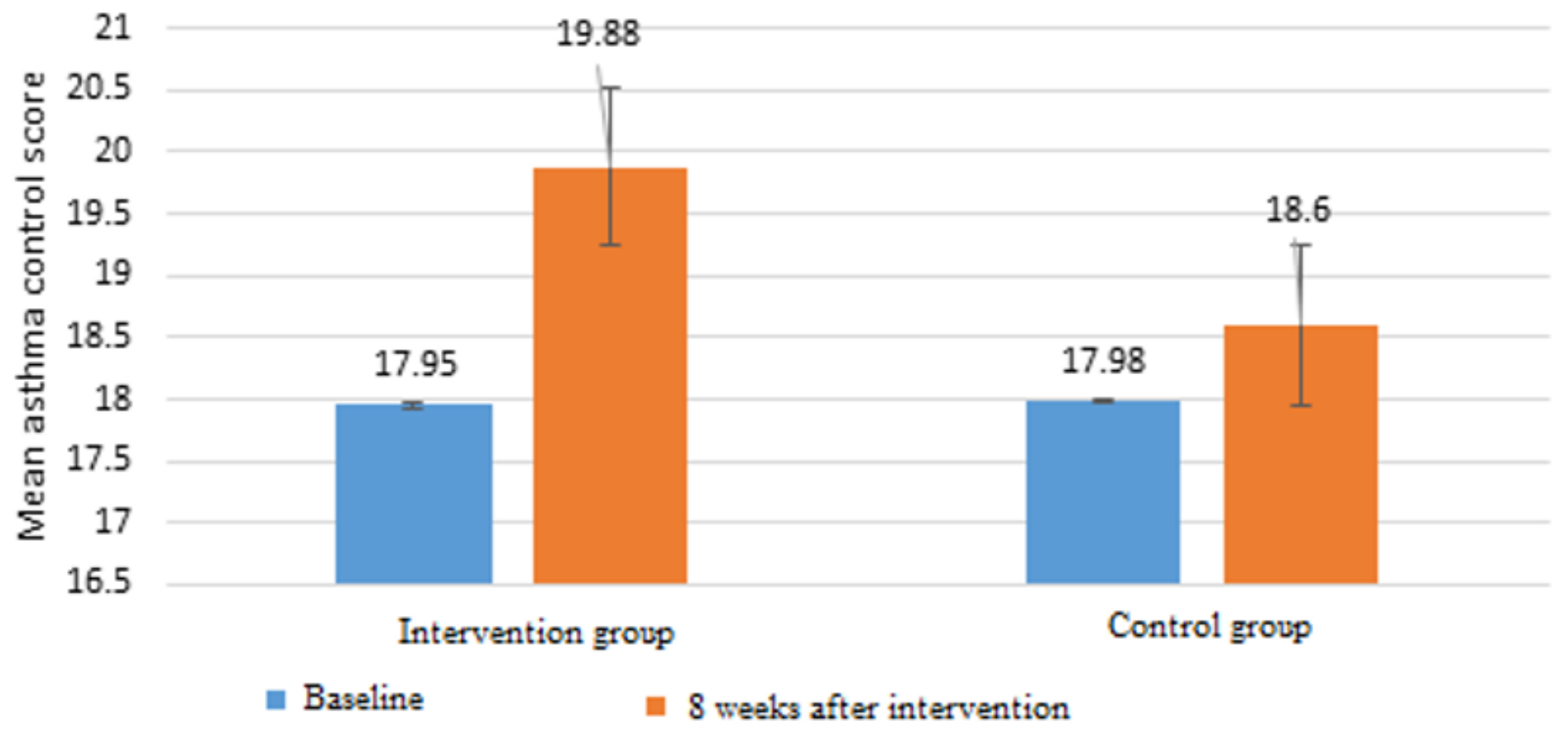

Figure 2

Comparison of mean asthma control scores between the groups

\section{Supplementary Files}

This is a list of supplementary files associated with this preprint. Click to download.

- CONSORT2010Checklist.doc 